\title{
DEVELOPMENT AND VALIDATION OF SPECTROFLUOROMETRIC METHOD FOR DETERMINATION OF PIOGLITAZONE HCL IN MARKETED AND NON-MARKETED PHARMACEUTICAL TABLET DOSAGE FORMS
}

\author{
HAMAD S. ALYAMI ${ }^{2 *}$, SAMER S. ABU- ALRUB ${ }^{2}$, MATER H. MAHNASHI ${ }^{2}$ \\ and ABDULLAH N. ALHARTHI ${ }^{3}$ \\ ${ }^{1}$ Department of Pharmaceutics, College of Pharmacy, \\ ${ }^{2}$ Department of Pharmaceutical Chemistry, College of Pharmacy, \\ ${ }^{3}$ Department of Pharmacology, College of Pharmacy, \\ Najran University, Najran, Saudi Arabia
}

\begin{abstract}
Pioglitazone hydrochloride is commonly used for the management of type-II diabetes. It is analyzed by various methods based on chromatographic techniques which are time and resource consuming. The objective of this study was to develop a simple, rapid, accurate, and cost-effective method for the analysis of pioglitazone hydrochloride in bulk and pharmaceutical dosage forms. In the present study, various experimental conditions were optimized according to USP and ICH guidelines. A solvent was selected based on the solubility while working wavelengths were selected based on the scan of a $1 \%$ solution, prepared in a selected solvent. Applicability of the method was assessed by the comparison of results with the developed method and methods reported for pioglitazone hydrochloride. The fluorescence intensity was measured in water/methanol solvent at 521 and at $260 \mathrm{~nm}$ for pioglitazone $\mathrm{HCl}$ excitation. Beer's law was obeyed in the concentration range of $0.02-0.06 \mu \mathrm{g} / \mathrm{mL}$, with a good correlation coefficient of R2, equal to 0.9613 between fluorescence intensity and concentration. The limit of detection (LOD) and the limit of quantification (LOQ) were 0.0102 and 0.0309 $\mu \mathrm{g} / \mathrm{mL}$, respectively. The method is applicable for the determination of pioglitazone $\mathrm{HCl}$ in different dosage forms with an average recovery of 85.36 to $103.0 \%$.
\end{abstract}

Keywords: pioglitazone $\mathrm{HCl}$, chromatographic, pharmaceutical dosage, fluorescence, wavelength, limit of detection (LOD), Limit of quantification (LOQ)

Diabetes mellitus is a group of metabolic diseases categorized by hyperglycemia resulting from defects in insulin secretion, which is further associated with the damage of other organs, such as the kidneys, heart, eyes, and blood vessels. Type-II diabetes is referred to as noninsulin-dependent diabetes and accounts for $90-95 \%$ of all diabetes patients (1). Most of the patients with type-II diabetes are obese as the excess weight itself causes some degree of insulin resistance (2). The management of Type-II diabetes involves various medications, among which thiazolidinediones are frequently prescribed (3). Pioglitazone $\mathrm{HCl}$ (PGZ) [5-[[4-[2-(5-ethylpyridin-2-yl) ethoxyphenyl [methyl]-1, 3-thiazolidine-2, 4-Dione], is a member of the thiazolidinedione class and which exerts its glucose-lowering effect by binding to peroxisome proliferator-activated receptors gamma, hence increasing the receptor sensitivity to insulin. After oral administration, it is rapidly absorbed with a bioavailability of $80 \%$, and the maximum blood plasma concentration is reached in about $1.5 \mathrm{~h}$. It is highly bound to proteins and excreted in the urine, with a plasma half-life of $7 \mathrm{~h}$ $(4,5)$.<smiles>O=C1NCC(=O)C(Cc2ccc(OCCc3ccc(CCl)cn3)cc2)S1</smiles>

Figure 1. Structural formula of pioglitazone $\mathrm{HCl}$.

* Corresponding author: e-mail: hsalmukalas@nu.edu.sa 
PGZ is a white crystalline powder, odorless, practically insoluble in water and slightly soluble in methanol (6). The molecular formula of PGZ and its structural formula is shown in Figure 1.

Several analytical methods based on different techniques, such as HPLC with UV detection, HPLC with tandem mass spectroscopy, potentiometry and spectrophotometry have been reported for the determination of PGZ in bulk and tablet dosage forms (7). There is no official method available for PGZ analysis and most of the reported methods are based on chromatography. These methods are time and resource consuming, especially during formulation development of a dosage form, where extensive evaluation is carried out. There is a need for a rapid, simple and accurate method of analysis for PGZ.

The objective of this study was to develop and validate a simple, faster, cost-effective, and environmentally friendly method for analysis of PGZ in bulk and dosage forms. In the present study, various experimental conditions were optimized and the developed method was validated for various parameters, like linearity, range, specificity, accuracy, and precision, according to USP and ICH guidelines (8). The application of the developed method was assessed by analysis of PGZ at different stages of product development and final dosage form (tablets).

\section{MATERIALS AND METHODS}

\section{Materials}

Pioglitazone Hydrochloride (purity 99.83\%) was purchased from Discovery Fine Chemicals (Dorset, UK). Analytical grade solvents (methanol) were purchased from Sigma Aldrich, New York, USA. Corn Starch, D-mannitol and magnesium stearate were obtained from Sigma-Aldrich New York, USA), whereas microcrystalline cellulose (MCC) Avicel PH-102 was purchased from Penwest Pharmaceutical Co. Patterson, New York. Actos ${ }^{\circledast}$ and Glados $^{\circledast}$ (15 mg pioglitazone $\left.\mathrm{HCl}\right)$ tablets were obtained from a community pharmacy at Najran, Saudi Arabia. Materials used in the formulation development were of pharmaceutical grade and used as received.

\section{Methods}

\section{Selection of solvent / Solubility of PGZ}

The solvent was selected based on the solubility. The solubility of PGZ in different solvents was determined by the flask shake method (9). A weighed amount of the drug was placed in a flask (250 mL) containing $50 \mathrm{~mL}$ and shaken on a mechanical flask shaker for 15 min, a further quantity of the drug was added and shaken. The process was continued until no more drug was solubilized. The solubility of PGZ was calculated using the following equation;

$$
\text { Solubility }=\frac{\text { Quantity of drug }(g)}{\text { Volume of solution }(m L)} \quad \text { Eq-1 }
$$

Solubility was determined in water, methanol, their mixture in $0.25: 0.75$ by volume.

\section{Selection of working wavelength}

The wavelength of maximum absorbance was selected based on scanning a solution of PGZ ( $1 \%$ $\mathrm{w} / \mathrm{v}$ ) prepared in a selected solvent. The wavelength at which maximum absorbance was observed was taken as the working wavelength for the developed method.

\section{Validation of the developed method}

The developed method was validated for various parameters like linearity, range, precision, and accuracy, according to ICH guidelines (10).

Various solutions of PGZ were prepared using a mixture of water and methanol as a solvent (15:85), in the concentration range of 0.01-0.1 $\mu \mathrm{g} / \mathrm{mL}$. The absorbance of the solutions was measured by a fluorescence spectrophotometer (Agilent carry 100 Eclipse) and plotted against the concentration. The curve was evaluated for linearity by regression analysis. The sensitivity of the method was determined based on the limit of detection (LOD) and limit of quantification (LOQ), calculated from the calibration curve. The accuracy of the method was assessed based on comparing the absorbance of the solution of pure API and the solution containing the excipients (intended to be used in the formulation of the PGZ tablets). The effect of the presence of the excipients on the instrumental response to the solution was evaluated and it indicated the accuracy of the method. The range of the proposed method was determined by measuring the absorbance of the solutions containing a quantity of PGZ equivalent to 80,100 and $120 \%$ of the nominal dose (11). The precision of the method was evaluated based on repeatability and intermediate precision. For repeatability, the analysis of the PGZ solution was repeated six times $(n=6)$ and the results were compared for variability. The intermediate precision comprised the intraday study and inter-day study. The solution of PGZ was analyzed at $8 \mathrm{~h}$ intervals for the first day (intraday study) and then at $24 \mathrm{~h}$ intervals for a further two days (inter-day study) and the results were evaluated. The stability of the PGZ solution in the solvent was evaluated for three days 
by keeping it at an ambient temperature $\left(18 \pm 2^{\circ} \mathrm{C}\right)$, a room temperature $\left(25 \pm 2^{\circ} \mathrm{C}\right)$ and a high temperature $\left(40 \pm 2^{\circ} \mathrm{C}\right)$. The percentage of recovery was calculated for each solution on a daily basis (at $24 \mathrm{~h}$ intervals) and compared with the variability.

\section{Formulation development of PGZ tablets}

The formulation of PGZ tablets was developed by a direct compression technique which involved the preparation of a powder blend and its compression into tablets. In the present study, two diluents (microcrystalline cellulose and starch) were evaluated for their suitability for direct compression. For evaluation of the effect of mixing on the characteristics of tablets, the powder blend was prepared using two methods: ordered mixing and geometric mixing.

The composition of different formulations is given in Table 1.

\section{Preparation of powder blend by ordered blending technique}

All the ingredients were weighed accurately as mentioned in Table 1. All the ingredients were sifted through a mesh (mesh \# 30) and blended in a labscale mixer for $15 \mathrm{~min}$ at $20 \mathrm{rpm}$. After mixing, the powder blend was kept in a sealed container until further evaluation.

\section{Preparation of powder blend by Geometric blend- ing technique}

For the preparation of the powder blend by geometric mixing, all the ingredients were weighed accurately, according to Table 1. API was taken in a lab-scale mixer, an equal amount of diluent was added and mixed for $5 \mathrm{~min}$. Another portion of diluents equal to the blended material was added and mixed for a further $5 \mathrm{~min}$. The process continued until all the ingredients were blended. Care was taken to add magnesium stearate only in the last mixing to avoid its over blending with the other materials. The powder blend was kept in a sealed container until further evaluation.

\section{Preparation of tablets}

The powder blend was compressed using a bench-top semi-automatic compression machine (Specac Limited, Slough, UK) fitted with flat punches having a diameter of $13 \mathrm{~mm}$. The compression weight of the tablet was $500 \mathrm{mg} /$ tablet. A compression force of three tons was applied for a period of $10 \mathrm{sec}$ and then released slowly.

\section{Statistical analysis}

Statistical analysis was performed using GraphPad Prism (Version 6.01, CA, USA). The analysis included a t-test, one-way analysis of variance (ANOVA) and the pair-wise multiple comparisons method (Tukey's test). The results were used for a comparison of data groups using mean and standard deviation (SD). The significant difference was determined using the probability value of $95 \%$ ( $\mathrm{p}<$ $0.05)$.

\section{RESULTS AND DISCUSSION}

PGZ is a poorly water-soluble drug and is available as a solid dosage (tablet) for oral administration. Most of the reported methods for the analysis of PGZ are based on chromatographic techniques, which are time and resource consuming. The objective of this study was to develop a simple, rapid and accurate method of analysis for PGZ based on spectrofluorimetry.

A solvent was selected based on the solubility of PGZ. It is practically insoluble in water and better solubility was observed in a mixture of water and methanol (12). To achieve better solubility, a mixture of water and methanol was selected as a solvent for the analysis of PGZ. Pioglitazone $\mathrm{HCl}$ has an aromatic ring that absorbs intensely and an excitation spectrum (13). A working wavelength was

Table 1. Composition of different formulations of PGZ tablets.

\begin{tabular}{|c|c|c|c|c|c|c|}
\hline Formulation Code & API & Starch & MCC & Mannitol & Mg.st & Blending Technique \\
\hline F1 & 3 & 30 & 0 & 66 & 1 & Ordered \\
\hline F2 & 3 & 0 & 30 & 66 & 1 & \\
\hline F3 & 3 & 30 & 0 & 66 & 1 & Geometric \\
\hline F4 & 3 & 0 & 30 & 66 & 1 & \\
\hline
\end{tabular}

Quantities are given as \%w/w; API; PGZ. 


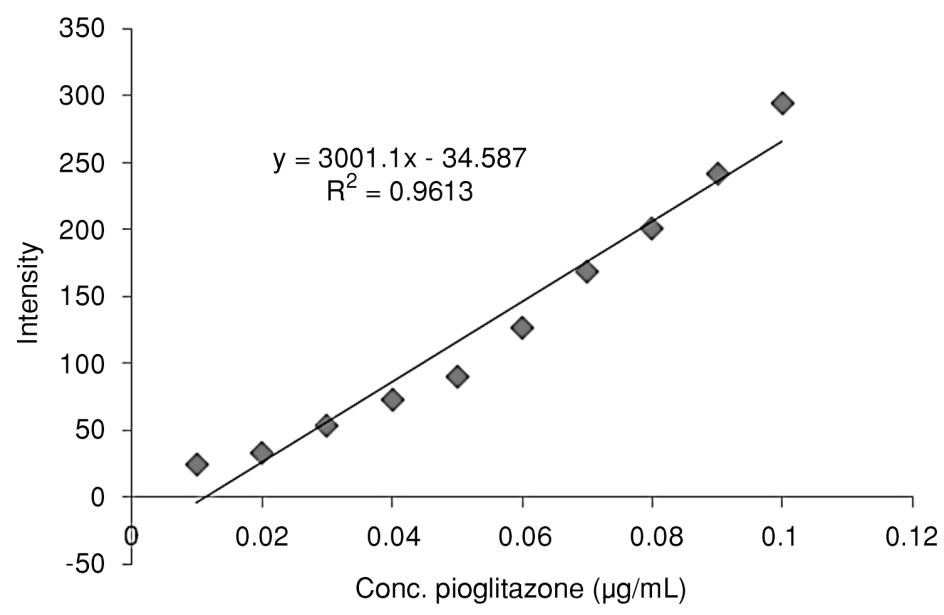

Figure 2. Calibration curve for pioglitazone $\mathrm{HCl}$.

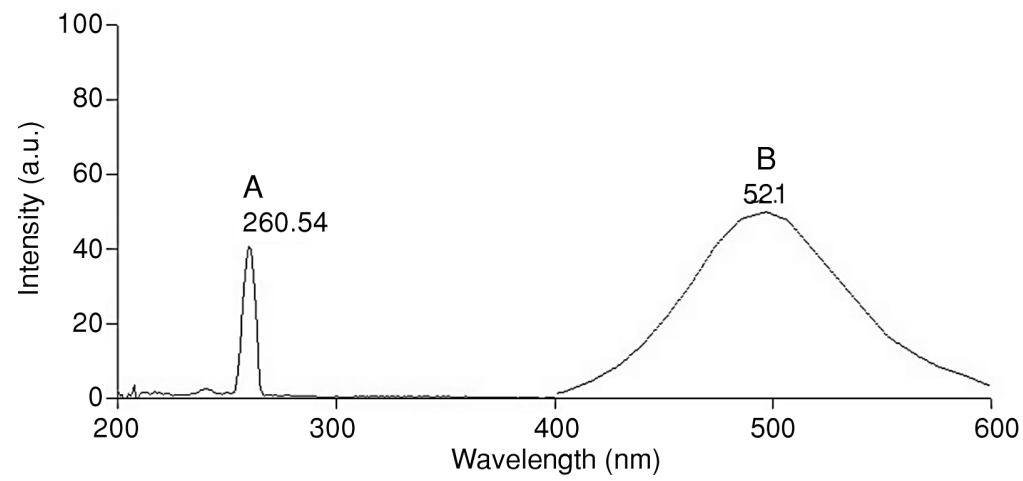

Figure 3. Fluorescence spectra of pioglitazone $\mathrm{HCl}$ in water/methanol. (A) Excitation spectrum; (B) Emission Spectrum.

Table 2. Optical characteristics data and validation parameters.

\begin{tabular}{|l|c|}
\hline Analytical performance characteristics & Data Pioglitazone $\mathrm{HCl}$ \\
\hline Wavelength of maximum absorbance & 260 \\
\hline Linear calibration range $(\mu \mathrm{g} / \mathrm{mL})$ & $0.02-0.06$ \\
\hline Regression equation & $\mathrm{Y}=3001.1 \mathrm{x}-34.587$ \\
\hline Correlation coefficient $(\mathrm{r})$ & 0.9613 \\
\hline Limit of detection $(\mu \mathrm{g} / \mathrm{mL})$ & 0.0102 \\
\hline Limit of quantitation $(\mu \mathrm{g} / \mathrm{mL})$ & 0.0309 \\
\hline Mean & 130.48 \\
\hline
\end{tabular}




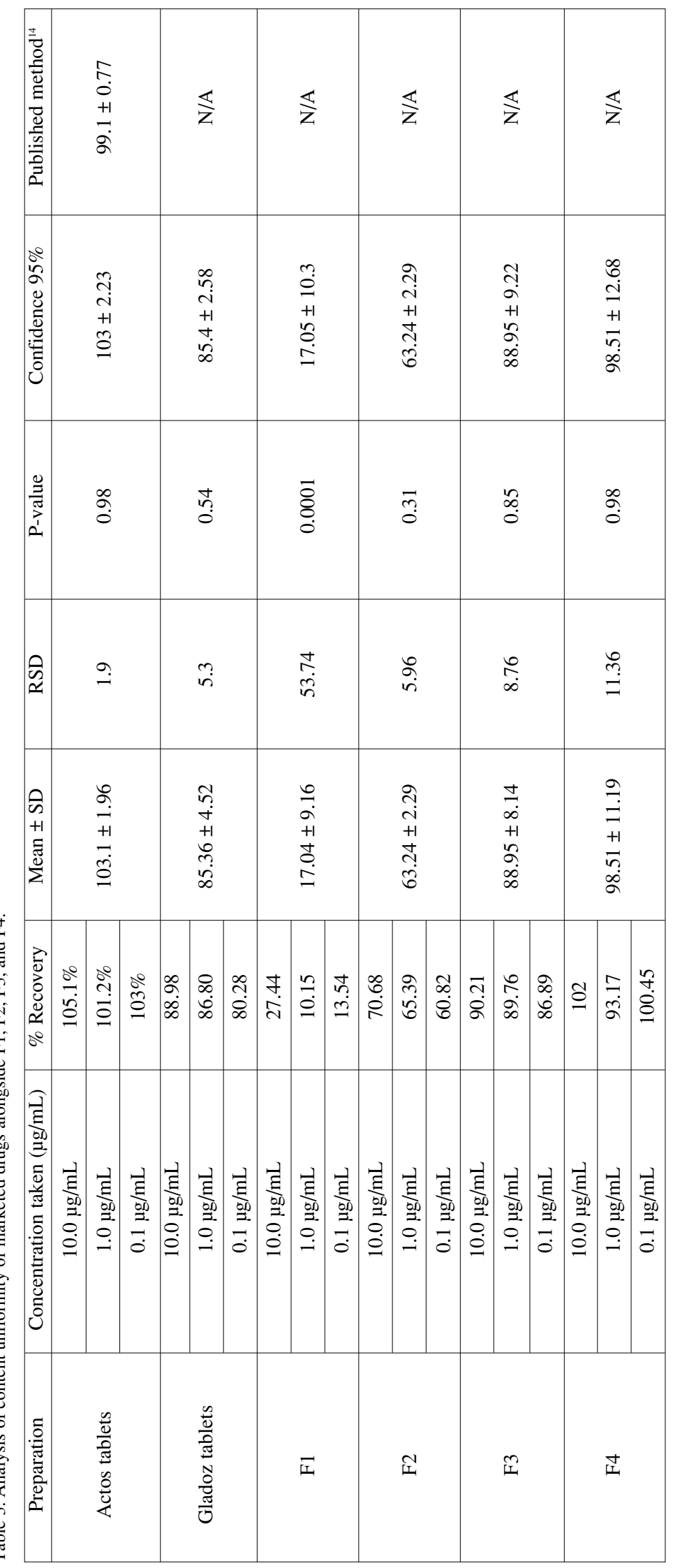


selected based on the scan of a $1 \%$ solution of PGZ prepared in a selected solvent (a mixture of water and methanol), as shown in Figure 3.

The developed method was validated according to the standard protocols as described by USP and $\mathrm{ICH}$.

The linearity of the method was determined in the concentration range of $0.01-0.1 \mu \mathrm{g} / \mathrm{mL}$ and the method was found linear in the given concentration range, as shown in Figure 2. The method showed better response with $100 \%$ recovery at three concentrations, equivalent to 80,100 and $120 \%$ of the nominal dose. It indicated that the method could be effectively used for the analysis of dosage forms. Results of the precision study showed that all the values were in close agreement with each other. Their standard deviation was below 2 and the percent recovery was above $99 \%$. The LOD and LOQ of the proposed method were very low, as shown in Table 2, and were suitable for the analysis of the bulk and pharmaceutical dosage forms of PGZ. The proposed method for the determination of pioglitazone in the tablet dosage form was found to be simple, accurate and rapid. The values of standard deviation were low and recovery was close to $98 \%$, indicating the effectiveness of the method.

Under the experimental conditions described, the calibration curve, LOD, LOQ, and regression equation were performed. Table 2 and Figure 2 show the results of the analysis of pioglitazone $\mathrm{HCl}$ and they obey Beer's law in the concentration range $0.02-0.06 \mu \mathrm{g} / \mathrm{mL}$ in the proposed method with a good correlation coefficient.

The limit of detection (LOD) and limit of quantitation (LOQ) of the spectrofluorometric method were determined at low concentrations of the standard solutions. The LOD of pioglitazone was found to be $0.0102 \mu \mathrm{g} / \mathrm{mL}$, and the LOQ was found to be $0.030 \mu \mathrm{g} / \mathrm{mL}$. The results are shown in Table 2.

\section{Analysis of developed formulation and marketed pharmaceutical product}

The developed method was applied for the analysis of PGZ during the formulation development and evaluation of the marketed product. Ten tablets were accurately weighed and the average weight per tablet was determined. The tablets were crushed to a fine powder and a powder equivalent to $15 \mathrm{mg}$ of pioglitazone $\mathrm{HCl}$ was added to a flask containing a mixture of water and methanol and agitated for $15 \mathrm{~min}$. The solution was filtered and its absorbance was measured at $260 \mathrm{~nm}$. The results of the analysis are reported in Table 3 . For comparison, the analysis was made using the reported method. The statistical analysis showed no significant difference between the results of the analysis performed by the developed method and by the reported method of prepared tablets using a geometric mixing technique and the published method concerning the accuracy, which recorded confidence of $95 \%$ and recovery. However, using the t-test, there was a significant difference between the marketed tablets, the tablets prepared using geometric mixing, and those prepared using ordered mixing $(\mathrm{p}<0.05)$. Geometric blending is a standard technique used to mix small amounts of drugs (14). Therefore, two formulations were prepared for the geometric blends using 30\% starch and 30\% MCC excipients, respectively (F3 and F4).

\section{CONCLUSION}

The developed spectrophotometric method is a simple, accurate, reproducible, and effective means for determining pioglitazone $\mathrm{HCl}$ in pharmaceutical tablet formulations. A mixture of water and methanol showed better solubility and was selected as the solvent. All the validation parameters were in accordance with standard guidelines (USP and $\mathrm{ICH})$. In the case of ordered mixing techniques for formulations, F1 and F2 failed to meet the required pharmacopeial standards for drug content uniformity. Therefore, geometric mixing was performed and showed considerable uniformity improvements for both carrier types. In general, the starch blends (F1 and F3) showed unacceptable uniformity with the drug, particularly when using ordered mixing, whereas with MCC the blend reached ideal uniformity at the end of geometric mixing. The study concluded that MCC demonstrated better drug content uniformity in both mixing techniques. Therefore, the values of average recovery make this method suitable for the determination of pioglitazone in a tablet dosage form.

\section{Acknowledgments}

The authors highly acknowledged the Ministry of Education and Deanship of Scientific Research, Najran University for funding this work; Project Code [NU/MID/17/004].

\section{Conflict of interest}

The authors confirm that this article content has no conflicts of interest. 


\section{REFERENCES}

1. Selvin E., Marinopoulos S., Berkenblit G., Rami T., Brancati F.L., et al.: Ann. Intern. Med. 6, 141 (2004).

2. Association A.D.: Diabetes Care 41, S13 (2018).

3. Kung J., Henry R.R.: Expert Opin. Drug Saf. 4, 11 (2012).

4. Eckland D., Danhof M.: Exp. Clin. Endocrinol. Diabetes 108, 234 (2000).

5. Jaakkola T., Backman J.T., Neuvonen M., Laitila J., Neuvonen P.J.: Br. J. Clin. Pharmacol. 1, 61 (2006).

6. Gillies P.S., Dunn C.J.: Drugs 2, 60 (2000).

7. Srinivasulu D., Sastry B., Omprakash G.: Int. J. Chem. Res. 1, 1 (2010).
8. ICH I, Editor Q2 (R1): Validation of analytical procedures: text and methodology. International Conference on Harmonization, Geneva 2005.

9. Soltanpour S., Acree W.E., Jouyban A.: AAPS PharmSciTech 4, 10 (2009).

10. Singh R., Saini P., Mathur S., Singh G., Lal B.: Indian J. Pharm. Sci.. 2, 72 (2010).

11. El-Zaher A.A., Elkady E.F., Elwy H.M., Saleh M.A.E.M.: Spectrochim. Acta A 182, 175 (2017).

12. Tao M., Sun H., Wang Z., Cui P., Wang J.: Fluid Ph. Equilibria 352, 14 (2013).

13. Beloshe S.P., Chougule D.D., Shah R.R., Ghodke D.S., Pawar N.D., Ghaste R.P.: Asian J. Pharm. 2, 4 (2014).

14. Venables H.J., Wells J.: Drug Dev. Ind. Pharm. 27, 7 (2001).

(C) 2020 by Polish Pharmaceutical Society. This is an access article under the CC BY NC license

(http://creativecommons.org/licenses/by-nc/4.0/). 